\title{
Mitral Annular Calcification Is Associated with Pulse Wave Velocity but Not with Augmentation Index
}

\author{
Ismet Durmus $^{\mathrm{a}}$ Kayıhan Karaman ${ }^{\mathrm{b}}$ Serkan Öztürk ${ }^{c} \quad$ Merih Kutlu $^{\mathrm{a}}$ \\ ${ }^{a}$ Department of Cardiology, Faculty of Medicine, Karadeniz Technical University, Trabzon, ${ }^{b}$ Kahramanmaraş State \\ Hospital, Kahramanmaraş, and ' Department of Cardiology, Faculty of Medicine, Abant İzzet Baysal University, \\ Bolu, Turkey
}

\section{Key Words}

Mitral annular calcification · Pulse wave velocity •

Augmentation index

\begin{abstract}
Objective: To investigate the possible relationship between mitral annular calcification (MAC) and arterial stiffness. Subjects and Methods: Forty-two patients (mean age $68 \pm 6$ years) with MAC and an age-matched control group of 41 individuals (mean age $66 \pm 6$ years) were studied. Arterial stiffness and wave reflections of the study population were evaluated by using applanation tonometry (SphygmoCor). Aortic pulse wave velocity (PWV) was measured as an index of aortic stiffness. The heart rate-corrected augmentation index (Alx@75) was estimated as a composite marker of wave reflections and arterial stiffness. Results: Aortic PWV was significantly higher in patients with MAC $(12.2 \pm 2.3$ $\mathrm{m} / \mathrm{s})$ than in controls $(10.1 \pm 1.3 \mathrm{~m} / \mathrm{s}, \mathrm{p}=0.0001)$. However, Alx@75 was similar between the groups ( $28 \pm 10$ vs. $29 \pm$ $10 \%, p=0.59$ ). Multivariate analysis involving the whole population revealed that brachial diastolic blood pressure $(\beta=$ $1.87, p=0.04)$ and MAC $(\beta=0.41, p=0.0001)$ were independent determinants of aortic PWV. Conclusion: The data
\end{abstract}

\section{KARGER}

E-Mail karger@karger.ch www.karger.com/mpp

\section{(c) 2012 S. Karger AG, Basel} $1011-7571 / 13 / 0222-0150 \$ 38.00 / 0$

Karger

Open access

This is an Open Access article licensed under the terms of the Creative Commons Attribution- NonCommercial-NoDerivs 3.0 License (www.karger.com/OA-license), applicable to the online version of the article only. Distribution for non-commercial purposes only. showed that MAC was significantly associated with increased arterial stiffness and that it was an independent determinant of aortic PWV.

Copyright $\odot 2012$ S. Karger AG, Basel

\section{Introduction}

Arterial stiffness is a well-established independent marker of cardiovascular risk in hypertensive patients and even in healthy individuals $[1,2]$. Arterial stiffness is a complex phenomenon consisting of several distinct processes including structural elements within the arterial wall, vascular smooth muscle tone, chronic low-grade inflammation, and endothelial dysfunction $[3,4]$. It is also known that several cardiovascular risk factors including age, smoking, hypertension, hypercholesterolemia, metabolic syndrome and type II diabetes are associated with increased arterial stiffness [4]. Thus, there is interest in factors affecting arterial stiffness as a strong indicator for development of cardiovascular disease.

Calcification of the mitral valve, known as mitral annular calcification (MAC), results from a chronic degenerative noninflammatory process. Previous studies have 
documented that patients with MAC have higher prevalences of atherosclerotic risk factors and different forms of atherosclerotic cardiovascular diseases $[5,6]$. It seems that the etiological process of increased arterial stiffness and MAC has large overlaps. Also MAC is suggested to be associated with left atrial dilatation [7], aortic atheroma [6] and impaired coronary microvascular function [8]. However, the potential association between MAC and arterial stiffness has not been thoroughly documented. Therefore, the aim of this study was to investigate whether an association exists between MAC and arterial stiffness.

\section{Subjects and Methods}

The study was performed between January and December 2009. All patients admitted to the Department of Cardiology, outpatient clinic of the Karadeniz Technical University Hospital, with echocardiography during this period were considered. Of these, 42 consecutive patients with MAC were prospectively enrolled in this study. Forty-one age- and gender-matched individuals were the control group. Detailed medical history, physical examination and routine biochemical tests were performed in addition to 12lead electrocardiograms. Valvular functions, left ventricular (LV) size and functions (ejection fraction), and left atrial diameter were evaluated by transthoracic echocardiography, as previously described [9]. The protocol of this study was approved by the Institution's Ethics Committee and written informed consent was obtained from each patient. Patients with hemolytic, inflammatory, malign, pulmonary, hepatic, and renal diseases, heart failure, valvular heart disease, congenital heart disease, ejection fraction less than $50 \%$, history of coronary artery disease or acute coronary syndromes, history of cardiac surgery, atrial fibrillation, and current pregnancy were excluded from the study.

\section{Echocardiographic Examination}

GE VingMed System 7 (Horten, Norway) was used to perform the echocardiographic examinations. The LV diameters were measured by using the American Society of Echocardiography M-mode technique [9]. Global LV function was assessed by measuring LV end-diastolic and end-systolic volumes and LV ejection fraction, using the modified biplane Simpson rule. Valvular heart disease was also assessed. MAC was defined as the presence of an intense echo-producing structure located at the level of the mitral annulus and in the atrioventricular groove by both 2-dimensional and M-mode echocardiographic findings on parasternal and apical views as described previously [10].

\section{Measurement of Pulse Wave Velocity}

Aortic pulse wave velocity (PWV) was determined with the foot-to-foot method using the SphygmoCor system (AtCor Medical, Sydney, Australia) [4]. Consecutive recordings of the carotid and femoral artery pulse waves were collected in an electrocardiogram-based manner and thus, the time latency between the appearance of each respective waves was calculated. The distance between the two sites was measured on the body surface. The to- tal distance between the carotid and femoral sites was used for the measurements. The average measurement over a period of $8 \mathrm{~s}(9-$ 10 cardiac cycles) was calculated after the exclusion of extreme values.

\section{Pressure Waveform Analysis}

Assessment of arterial wall properties and wave reflection characteristics was performed noninvasively using the SphygmoCor system. Radial artery pressure waveforms were recorded at the wrist, using applanation tonometry with a high-fidelity micromanometer (Millar Instruments, Houston, Tex., USA). After 20 sequential waveforms had been acquired and averaged, a validated generalized mathematical transfer function was used to synthesize the corresponding central aortic pressure waveform [11]. The AIx and augmentation pressure (AP) were derived from this with the technique of pressure waveform analysis [4]. The merging point of the incident and the reflected wave (the inflection point) was identified on the generated aortic pressure waveform. AP was the maximum systolic blood pressure minus pressure at the inflection point. The AIx was defined as the AP divided by pulse pressure and expressed as a percentage. Larger values of AIx indicate increased wave reflection from the periphery or earlier return of the reflected wave as a result of increased PWV (attributable to increased arterial stiffness). The AIx is dependent upon the elastic properties of the entire arterial tree (elastic and muscular arteries). In addition, because AIx is influenced by heart rate, an index normalized to a heart rate of $75 \mathrm{bpm}$ (AIx@75) was used in accordance with Wilkinson et al. [12]. Only high-quality recordings, defined as an in-device quality index of $>80 \%$ (derived from an algorithm including average pulse height, pulse height variation, diastolic variation, and the maximum rate of rise of the peripheral waveform), and acceptable curves on visual inspection, were included in the analysis. All measurements were performed by the same person with the patient in the supine position in a quiet temperature-controlled room after a brief rest period of at least $5 \mathrm{~min}$.

\section{Statistical Analyses}

Continuous data are expressed as mean $\pm \mathrm{SD}$. Comparison between two groups was performed using the unpaired $t$ test or nonparametric means test (Mann-Whitney U test) for continuous variables, and the Fisher exact test for categoric variables. Correlations between variables were evaluated by calculation of the Pearson correlation coefficient. Multiple linear regression analysis was used to identify significant determinants of arterial stiffness parameters (AIx@75, PWV). For multiple regressions, factors showing a value of $\mathrm{p}<0.1$ in univariate analysis were selected. A $p$ value of $<0.05$ was considered statistically significant. Statistical analyses were performed using SPSS software (version 10.0, SPSS, Chicago, Ill., USA).

\section{Results}

\section{Patient Characteristics}

Baseline clinical and demographic characteristics of the study population are given in table 1 . There were no significant differences between the groups in terms of age, 
gender, smoking status, heart rate, body mass index, fasting glucose, serum creatinine, and lipid profiles. There was no difference between the groups with respect to medication usage. Despite the distribution of number of hypertensive individuals in both groups being designed as equal, the systolic blood pressure values of the MAC group were significantly higher $(138 \pm 18 \mathrm{~mm} \mathrm{Hg})$ than those of the control group $(129 \pm 18 \mathrm{~mm} \mathrm{Hg})(\mathrm{p}=0.02)$.

\section{Baseline Echocardiographic Characteristics}

There were no significant differences between the groups with respect to LV end-systolic diameter (29 \pm 6 vs. $29 \pm 4 \mathrm{~mm}, \mathrm{p}=0.62)$, LV end-diastolic diameter (45 \pm 4 vs. $46 \pm 3 \mathrm{~mm}, \mathrm{p}=0.17), \mathrm{LV}$ end-systolic volume ( 28 \pm 9 vs. $31 \pm 11 \mathrm{ml}, \mathrm{p}=0.17)$, LV end-diastolic volume $(76 \pm 18$ vs. $80 \pm 15 \mathrm{ml}, \mathrm{p}=0.22)$ and ejection fraction $(65 \pm 5$ vs. $65 \pm 4 \%, \mathrm{p}=0.8)$. Patients with MAC had a greater posterior wall ( $12 \pm 2$ vs. $11 \pm 1 \mathrm{~mm}, \mathrm{p}=0.002)$, interventricular septum $(11 \pm 1$ vs. $10 \pm 1 \mathrm{~mm}, \mathrm{p}=$ $0.001)$ and left atrial diameter $(38 \pm 4$ vs. $36 \pm 4 \mathrm{~mm}$, $\mathrm{p}=0.03)$ than controls.

\section{Pulse Wave Analysis and Velocity}

The indices of arterial stiffness and wave reflections of the study population are presented in table 2. Central aortic systolic and diastolic pressure, AP and AIx@75 (fig. 1) were similar between the groups. Aortic PWV values (fig. 2) were significantly higher in patients with MAC than control subjects.

\section{Determinants of $P W V$}

In bivariate correlation analysis, significant correlations were found between PWV and brachial systolic blood pressure $(\mathrm{r}=0.31, \mathrm{p}=0.003)$, brachial diastolic blood pressure $(\mathrm{r}=0.2, \mathrm{p}=0.06)$, brachial mean pressure $(\mathrm{r}=0.21, \mathrm{p}=0.05)$, aortic systolic blood pressure $(\mathrm{r}=0.24$, $\mathrm{p}=0.02)$ and aortic mean pressure $(\mathrm{r}=0.21, \mathrm{p}=0.05$; table 3). Also PWV values did not differ between smokers and nonsmokers, genders, and current medication (table 4). Multiple regression analyses were performed for identifying factors that determine the PWV. Significant determinants of PWV were brachial diastolic blood pressure $(\beta=1.87, \mathrm{p}=0.04)$ and $\mathrm{MAC}(\beta=0.41, \mathrm{p}=0.0001)$.

\section{Discussion}

PWV as an index of large arterial stiffness was higher in subjects with MAC; however, AIx@75 as a composite marker of wave reflections and arterial stiffness was sim-
Table 1. Clinical characteristics and laboratory values of the study population

\begin{tabular}{|c|c|c|c|}
\hline & $\begin{array}{l}\text { MAC } \\
(n=42)\end{array}$ & $\begin{array}{l}\text { Control } \\
(\mathrm{n}=41)\end{array}$ & $\mathrm{p}$ \\
\hline Age, years & $68 \pm 6$ & $66 \pm 6$ & 0.1 \\
\hline Male, $\%$ & 34 & 39 & 0.1 \\
\hline Hypertension, \% & 67 & 66 & 0.9 \\
\hline Diabetes mellitus, \% & 26 & 27 & 0.9 \\
\hline Smoking, \% & 21 & 22 & 0.9 \\
\hline Glucose, mg/dl & $104 \pm 34$ & $106 \pm 25$ & 0.7 \\
\hline Creatinine, mg/dl & $0.84 \pm 0.23$ & $0.89 \pm 0.17$ & 0.3 \\
\hline Body mass index & $30 \pm 4$ & $31 \pm 4$ & 0.7 \\
\hline Heart rate, bpm & $66 \pm 10$ & $68 \pm 11$ & 0.4 \\
\hline Systolic BP, mm Hg & $138 \pm 18$ & $129 \pm 18$ & 0.02 \\
\hline Diastolic BP, mm Hg & $78 \pm 12$ & $79 \pm 12$ & 0.5 \\
\hline Mean BP, mm Hg & $99 \pm 13$ & $98 \pm 14$ & 0.7 \\
\hline LDL cholesterol, mg/dl & $135 \pm 41$ & $132 \pm 26$ & 0.6 \\
\hline HDL cholesterol, mg/dl & $43 \pm 10$ & $45 \pm 10$ & 0.4 \\
\hline Total cholesterol, mg/dl & $195 \pm 49$ & $205 \pm 32$ & 0.3 \\
\hline Triglyceride, mg/dl & $162 \pm 69$ & $175 \pm 77$ & 0.4 \\
\hline Aspirin, \% & 50 & 41 & 0.4 \\
\hline$\beta$-Blockers, $\%$ & 33 & 29 & 0.7 \\
\hline ACE inhibitors, \% & 43 & 41 & 0.9 \\
\hline $\mathrm{ARB}, \%$ & 24 & 27 & 0.7 \\
\hline Diuretic, \% & 14 & 20 & 0.5 \\
\hline Ca channel blocker, \% & 10 & 2 & 0.2 \\
\hline Statins, $\%$ & 21 & 20 & 0.8 \\
\hline
\end{tabular}

$\mathrm{BP}=$ Blood pressure; $\mathrm{LDL}=$ low-density lipoprotein; $\mathrm{HDL}=$ high-density lipoprotein; $\mathrm{ACE}=$ Angiotensin-converting enzyme; ARB = angiotensin receptor blockers.

Table 2. Pulse wave analysis and velocity in the study groups

$\begin{array}{lll}\text { MAC } & \text { Control } & p \\ (n=42) & (n=41) & \end{array}$

$\begin{array}{lrrl}\text { Central aortic pressure, } \mathrm{mm} \mathrm{Hg} & & \\ \quad \text { Systolic } & 127 \pm 16 & 121 \pm 18 & 0.11 \\ \quad \text { Diastolic } & 79 \pm 12 & 80 \pm 12 & 0.51 \\ \text { Mean } & 99 \pm 13 & 98 \pm 14 & 0.7 \\ \mathrm{PWV}, \mathrm{m} / \mathrm{s} & 12.2 \pm 2.3 & 10.1 \pm 1.3 & <0.0001 \\ \mathrm{AP}, \mathrm{mm} \mathrm{Hg} & 16 \pm 6 & 16 \pm 10 & 0.81 \\ \text { AIx@75, \% } & 28 \pm 10 & 29 \pm 10 & 0.59\end{array}$

ilar in both groups and MAC was independent of the higher value of PWV.

The findings that MAC and brachial diastolic blood pressure were independent determinants of PWV confirmed previous observations that showed an association 


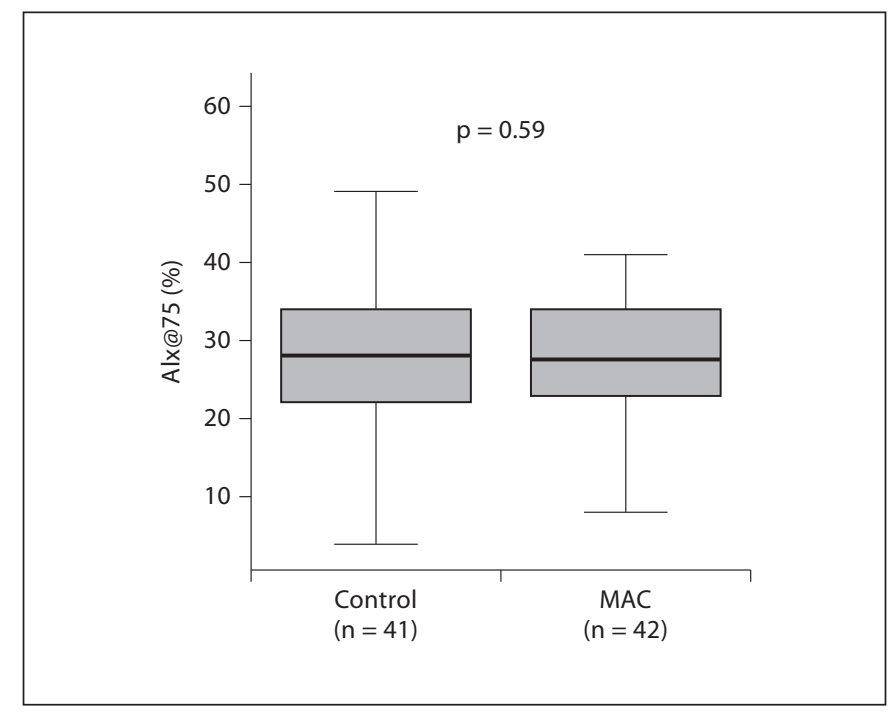

Fig. 1. Heart rate-corrected augmentation index in study groups.

Table 3. Bivariate correlation analysis between PWV and other variables

\begin{tabular}{lll}
\hline & $\mathrm{r}$ & $\mathrm{p}$ \\
\hline Age & 0.1 & 0.3 \\
Glucose & 0.08 & 0.4 \\
Creatinine & 0.1 & 0.2 \\
Total cholesterol & -0.07 & 0.4 \\
Triglyceride & -0.03 & 0.7 \\
LDL cholesterol & -0.02 & 0.8 \\
HDL cholesterol & -0.09 & 0.4 \\
Body mass index & -0.12 & 0.2 \\
Brachial SP & 0.31 & 0.003 \\
Brachial DP & 0.2 & 0.06 \\
Brachial MP & 0.21 & 0.05 \\
Aortic SP & 0.24 & 0.02 \\
Aortic DP & 0.18 & 0.08 \\
Aortic MP & 0.21 & 0.05 \\
\hline
\end{tabular}

LDL = Low-density lipoprotein; HDL = high-density lipoprotein; $\mathrm{SP}=$ systolic pressure; $\mathrm{DP}=$ diastolic pressure; $\mathrm{MP}=$ mean pressure.

between blood pressure and PWV [1,3]. Although the number of allocated hypertensive patients was similar in both groups, brachial systolic blood pressure was significantly higher in subjects with MAC than in controls. However, the difference between the central aortic pressure values of the groups was not statistically significant. Both the univariate and multivariate analyses yielded a

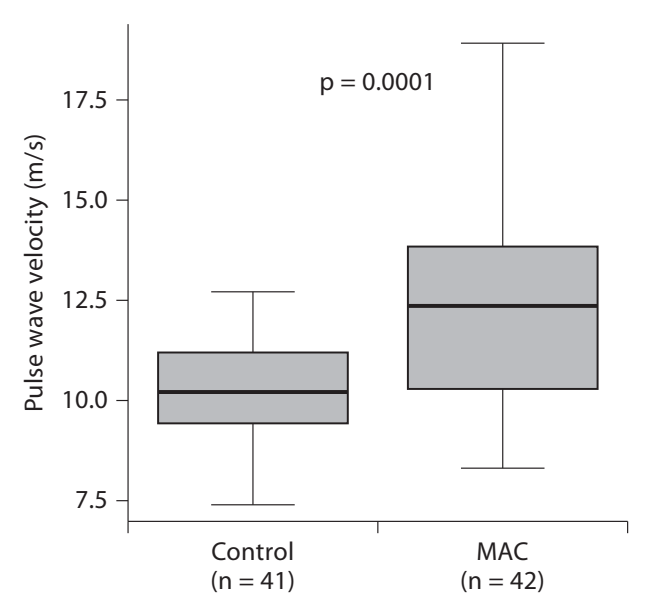

Fig. 2. Aortic PWV in study groups.

Table 4. Baseline characteristic and PWV

\begin{tabular}{lccc}
\hline & \multicolumn{2}{c}{$\mathrm{PWV}, \mathrm{m} / \mathrm{s}$} & $\mathrm{p}$ \\
\cline { 2 - 3 } & + & & \\
\hline Male & $11.6 \pm 2$ & $10.9 \pm 2.2$ & 0.1 \\
Hypertension & $11.2 \pm 2$ & $11.1 \pm 2.4$ & 0.8 \\
Diabetes mellitus & $10.8 \pm 1.7$ & $11.3 \pm 2.3$ & 0.4 \\
Smoking & $11.3 \pm 2.1$ & $11.1 \pm 2.2$ & 0.7 \\
Aspirin & $11.1 \pm 1.9$ & $11.2 \pm 2.4$ & 0.8 \\
B-Blockers & $11.1 \pm 1.4$ & $11.2 \pm 1.4$ & 0.8 \\
ACE & $11.0 \pm 2$ & $11.3 \pm 2.3$ & 0.5 \\
ARB & $10.6 \pm 1.6$ & $11.3 \pm 2.3$ & 0.1 \\
Statin & $11 \pm 1.4$ & $11.2 \pm 2.3$ & 0.7 \\
Diuretic & $11.1 \pm 2.2$ & $11.1 \pm 2.1$ & 0.9 \\
Ca channel blocker & $12.9 \pm 2.5$ & $11.0 \pm 2.1$ & 01 \\
\hline
\end{tabular}

$\mathrm{ACE}=$ Angiotensin-converting enzyme; $\mathrm{ARB}=$ angiotensin receptor blockers; + = present; - = absent.

significant relationship between MAC and PWV, but this relationship could not be explained by systolic high blood pressures in subjects with MAC.

Several mechanisms may explain the determined relationship between MAC and PWV. In previous studies, MAC was reported to be associated with both coronary risk factors and cardiovascular diseases $[5,6,13]$. These 
results clearly indicated significant associations between both cardiovascular risk factors and different measures of subclinical atherosclerosis and valvular calcification, thereby providing additional evidence for the hypothesis that annular calcification is atherosclerotic in nature [14]. In addition, MAC might be accepted as a manifestation of atherosclerosis because it shares similar histopathological findings [15]. Adler et al. [5] showed the presence of foam cells on the posterior mitral leaflet in patients with MAC. We cannot explain the observed association between mitral annulus calcification, a noninflammatory process, and atherosclerosis, a prominent inflammatory process, in this study. However, Fox et al. [16] showed that inflammatory markers were elevated in patients with valvular calcium. Although we have not measured inflammatory parameters in the current study, the abovementioned processes indicate that some changes may also take place in MAC. It is also well known that atherosclerotic changes in vascular tissue are related to arterial stiffness $[17,18]$. Increased arterial stiffness may be associated with atherosclerotic changes in subjects with MAC. An additional important mechanism that should also be considered in MAC is calcification [19]. Indeed patients with MAC had been reported to have increased vascular calcification [20], which takes place through complex yet undeciphered mechanisms that cause structural changes in large arteries [21]. Because it has been established that vascular calcification leads to increased PWV $[22,23]$, it is conceivable that patients with MAC could have increased PWV.

The measurement of aortic PWV is generally accepted as the most simple, noninvasive, reproducible model for determining arterial stiffness; hence, it is considered as the 'gold standard' measurement of arterial stiffness [4]. It has also been used in epidemiological studies demonstrating the predictive value of aortic stiffness for cardiovascular events $[24,25]$. Our finding that MAC was significantly associated with PWV but not with AIx@75. This is in agreement with previous studies $[26,27]$ showing that aortic stiffness and wave reflection indices do not always change in parallel. Gedikli et al. [26] reported that low total antioxidant capacity levels were associated with AIx@75 but not with PWV [26]. Furthermore, Vlachopoulos et al. [27] have shown that acute systemic inflammation causes an increase in arterial stiffness and a decrease in wave reflection in healthy individuals. This difference may arise from the fact that these parameters reflect different aspects of arterial stiffness. AIx@75 is primarily determined by the magnitude and timing of reflected pressure waves, which depends on the tone of the resistance arteries [28]. The carotid-femoral PWV is a measure of elastic-type large artery stiffness, which depends on the structural remodeling of large elastic arteries [4]. Therefore, the observed increased PWV but not AIx@75 in patients with MAC is understandable, probably due to the more prominent impact of MAC on the aorta than the peripheral arteries, and this should also be considered.

The existence of an association between MAC and mortality and cardiovascular disease is well documented $[5,6,29]$. In this respect, Bozbas et al. [8] demonstrated that coronary microvascular function is impaired in patients with MAC. Also, MAC has been shown to be associated with increased left atrial diameter [7], increased incidence of atrial fibrillation [30], aortic atheroma [6] and conduction defects [31]. In addition to these findings, we successfully identified a significant relationship between MAC and altered vascular function in the current study.

The present study has some limitations, which include the small number of patients involved. Furthermore, since arterial stiffness, the main parameter of our study, reflects structural and functional changes of large arteries, it is difficult to predict all systemic factors and other impacts on vessel structures, and this fact should also be considered when interpreting our results.

\section{Conclusion}

MAC was independently associated with PWV and may contribute significantly to the development of arterial damage. For a more conclusive statement on the relationship between MAC and arterial stiffness, there is a need for further larger-scale studies.

\footnotetext{
References

1 Laurent S, Boutouyrie P, Asmar R, Gautier I, Laloux B, Guize L, Ducimetiere P, Benetos A: Aortic stiffness is an independent predictor of all-cause and cardiovascular mortality in hypertensive patients. Hypertension 2001; 37:1236-1241.

-2 Nurenberger J, Keflioglu-Scheiber A, Opazo Saez AM, Wenzel RR, Philipp T, Schafers RF: Augmentation index is associated with cardiovascular risk. J Hypertens 2002;20:24072414.

-3 Laurent S, Boutouyrie P: Recent advances in arterial stiffness and wave reflection in human hypertension. Hypertension 2007; 49 : 1202-1206.
} 
4 Laurent S, Cockcroft J, Van Bortel L, Boutouyrie P, Giannattasio C, Hayoz D, Pannier B, Vlachopoulos C, Wilkinson I, StruijkerBoudier $\mathrm{H}$, et al: Expert consensus document on arterial stiffness: methodological issues and clinical applications. Eur Heart J 2006; 27:2588 -2605.

5 Adler Y, Koren A, Fink N, Tanne D, Fusman R, Assali A, Yahav J, Zelikovski A, Sagie A: Association between mitral annulus calcification and carotid atherosclerotic disease. Stroke 1998;29:1833-1837.

6 Adler Y, Vaturi M, Fink N, Tanne D, Shapira Y, Weisenberg D, Sela N, Sagie A: Association between mitral annulus calcification and aortic atheroma: a prospective transesophageal echocardiographic study. Atherosclerosis 2000;152:451-456.

-7 Ariyarajah V, Apiyasawat S, Barac I, Spodick $\mathrm{DH}$ : Is the presence of mitral annular calcification associated with poor left atrial function? Echocardiography 2009;26:877-884.

8 Bozbas H, Pirat B, Yildirir A, Simşek V, Sade E, Altin C, Muderrisoglu H: Mitral annular calcification associated with impaired coronary microvascular function. Atherosclerosis 2008;98:115-121.

-9 Lang RM, Bierig M, Devereux RB, Flachskampf FA, Foster E, Pellikka PA, Picard MH, Roman MJ, Seward J, Shanewise J, et al, American Society of Echocardiography's Nomenclature and Standards Committee, Task Force on Chamber Quantification, American College of Cardiology Echocardiography Committee, American Heart Association, European Association of Echocardiography, European Society of Cardiology: Recommendations for chamber quantification. Eur J Echocardiogr 2006;7:79-108.

10 Adler Y, Herz I, Vaturi M, Fusman R, ShohatZabarski R, Fink N, Porter A, Shapira Y, Assali A, Sagie A: Mitral annular calcium detected by transthoracic echocardiography is a marker for high prevalence and severity of coronary artery disease in patients undergoing coronary angiography. Am J Cardiol 1998;82:1183-1186.

11 Pauca AL, O’Rourke MF, Kon ND: Prospective evaluation of a method for estimating ascending aortic pressure from the radial artery pressure waveform. Hypertension 2001; 38:932-937.

12 Wilkinson IB, MacCallum H, Flint L, Cockcroft JR, Newby DE, Webb DJ: The influence of heart rate on augmentation index and central arterial pressure in humans. J Physiol 2000;525:263-270.
13 Wong ND, Sciammarella M, Arad Y, Miranda-Peats R, Polk D, Hachamovich R, Friedman J, Hayes S, Daniell A, Berman DS: Relation of thoracic aortic and aortic valve calcium to coronary artery calcium and risk assessment. Am J Cardiol 2003;92:951-955.

14 Jayalath RW, Mangan SH, Golledge J: Aortic calcification. Eur J Vasc Endovasc Surg 2005; 30:476-488.

15 AllisonWA, Cheung P, Criqui MH, Langer RD, Wright CM: Mitral and aortic annular calcification are highly associated with systemic calcified atherosclerosis. Circulation 2006;113:861-866.

16 Fox CS, Guo CY, Larson MG, Vasan RS, Parise H, O'Donnell CJ, D'Agostino RB Sr, Keaney JF Jr, Benjamin EJ: Relations of inflammation and novel risk factors to valvular calcification. Am J Cardiol 2006;97:15021505.

17 Liu CS, Li CI, Shih CM, Lin WY, Lin CH, Lai SW, Li TC, Lin CC: Arterial stiffness measured as pulse wave velocity is highly correlated with coronary atherosclerosis in asymptomatic patients. J Atheroscler Thromb 2011;18:652-658.

18 Tsuchikura S, Shoji T, Kimoto E, Shinohara K, Hatsuda S, Koyama H, Emoto M, Nishizawa Y: Central versus peripheral arterial stiffness in association with coronary, cerebral and peripheral arterial disease. Atherosclerosis 2010;211:480-485.

19 Tenenbaum A, Fisman EZ, Pines A, Shemesh J, Shapira I, Adler Y, Frenkel Y, Boyko V, Motro M: Gender paradox in cardiac calcium deposits in middle-aged and elderly patients: mitral annular and coronary calcifications interrelationship. Maturitas 2000;36: 35-42.

20 Wang AY, Ho SS, Wang M, Liu EK, Ho S, Li PK, Lui SF, Sanderson JE: Cardiac valvular calcification as a marker of atherosclerosis and arterial calcification in end-stage renal disease. Arch Intern Med 2005;165:327-332.

21 Roman-Garcia P, Rodriguez-Garcia M, Cabezas-Rodriguez I, Lopez-Ongil S, Diaz-Lopez B, Cannata-Andia JB: Vascular calcification in patients with chronic kidney disease: types, clinical impact and pathogenesis. Med Princ Pract 2011;20:203-212.
22 Temmar M, Liabeuf S, Renard C, Czernichow S, Esper NE, Shahapuni I, Presne C, Makdassi R, Andrejak M, Tribouilloy C, et al: Pulse wave velocity and vascular calcification at different stages of chronic kidney disease. J Hypertens 2010;28:163-169.

23 Blaha MJ, Budoff MJ, Rivera JJ, Katz R, O'Leary DH, Polak JF, Takasu J, Blumenthal RS, Nasir K: Relationship of carotid distensibility and thoracic aorta calcification: multiethnic study of atherosclerosis. Hypertension 2009;54:1408-1415.

24 Mitchell GF, Hwang SJ, Vasan RS, Larson MG, Pencina MJ, Hamburg NM, Vita JA, Levy D, Benjamin EJ: Arterial stiffness and cardiovascular events: the Framingham Heart Study. Circulation 2010;121:505-511.

- 25 Shokawa T, Imazu M, Yamamoto H, Toyofuku M, Tasaki N, Okimoto T, Yamane K, Kohno N: Pulse wave velocity predicts cardiovascular mortality: findings from the $\mathrm{Ha}$ waii-Los Angeles-Hiroshima study. Circ J 2005;69:259-264.

26 Gedikli O, Ozturk S, Yilmaz H, Baykan M, Kiris A, Durmus I, Karaman K, Karahan C, Celik S: Low total antioxidative capacity levels are associated with augmentation index but not pulse-wave velocity. Heart Vessels 2009;24:366-370.

27 Vlachopoulos C, Dima I, Aznaouridis K, Vasiliadou C, Ioakeimidis N, Aggeli C, Toutouza M, Stefanadis C: Acute systemic inflammation increases arterial stiffness and decreases wave reflections in healthy individuals. Circulation 2005;112:2193-2200.

28 Nichols WW, O'Rourke MF: McDonald's Blood Flow in Arteries: Theoretical, Experimental and Clinical Principles. London, Arnold, 1998, pp 170-222.

29 Potpara TS, Vasiljevic ZM, Vujisic-Tesic BD, Marinkovic JM, Polovina MM, Stepanovic JM, Stankovic GR, Ostojic MC, Lip GY: Mitral annular calcification predicts cardiovascular morbidity and mortality in middleaged patients with atrial fibrillation: the Belgrade Atrial Fibrillation Study. Chest 2011;140:902-910.

- 30 Fox CS, Parise H, Vasan RS, Levy D, O'Donnell CJ, D'Agostino RB, Plehn JF, Benjamin EJ: Mitral annular calcification is a predictor for incident atrial fibrillation. Atherosclerosis 2004;173:291-294.

- 31 Nair CK, Runco V, Everson GT, Boghairi A, Mooss AN, Mohiuddin SM, Sketch MH: Conduction defects and mitral annulus calcification. Br Heart J 1980;44:162-167. 